OPEN ACCESS

Edited by:

Magdalena Plebanski, Monash University, Australia

Reviewed by:

Hridayesh Prakash,

University of Hyderabad, India

Peter Smooker,

RMIT University, Australia

*Correspondence:

Kai Wei

weikaisdau@163.com

Ruiliang Zhu

zhur11963@163.com

tThese authors have contributed equally to this work.

Specialty section: This article was submitted to Microbial Immunology, a section of the journal

Frontiers in Microbiology

Received: 16 October 2015 Accepted: 14 January 2016

Published: 02 February 2016

Citation:

Zhu F, Liu X, Sun Z, Yu C, Liu L, Yang S, Li B, Wei K and Zhu R (2016) Immune-Enhancing Effects of Taishan Pinus massoniana Pollen Polysaccharides on DNA Vaccine Expressing Bordetella avium ompA.

Front. Microbiol. 7:66.

doi: 10.3389/fmicb.2016.00066

\section{Immune-Enhancing Effects of Taishan Pinus massoniana Pollen Polysaccharides on DNA Vaccine Expressing Bordetella avium ompA}

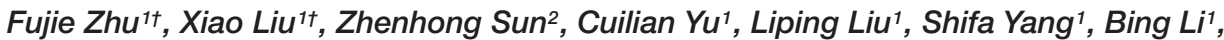
Kai Wei ${ }^{1 *}$ and Ruiliang $\mathrm{Zhu}^{1 *}$

${ }^{1}$ Laboratory of Animal Biological Products, College of Animal Science and Technology, Shandong Agricultural University, Taian, China, ${ }^{2}$ Analytic Laboratory, Institute of Preclinical Medicine, Taishan Medical College, Taian, China

Bordetella avium is the causative agent of bordetellosis, which remains to be the cause of severe losses in the turkey industry. Given the lack of vaccines that can provide good protection, developing a novel vaccine against $B$. avium infection is crucial. In this study, we constructed a eukaryotic expression plasmid, which expressed the outer membrane protein $A$ (ompA) of $B$. avium, to prepare a $B$. avium recombinant ompADNA vaccine. Three concentrations (low, middle, and high) of Taishan Pinus massoniana pollen polysaccharides (TPPPS), a known immunomodulator, were used as adjuvants, and their immune conditioning effects on the developed DNA vaccine were examined. The pure ompA-DNA vaccine, Freund's incomplete adjuvant ompA-DNA vaccine, and the empty plasmid served as the controls. The chickens in each group were separately inoculated with these vaccines three times at 1, 7, and 14 days old. Dynamic changes in antibody production, cytokine secretion, and lymphocyte count were then determined from 7 to 49 days after the first inoculation. Protective rates of the vaccines were also determined after the third inoculation. Results showed that the pure DNA vaccine obviously induced the production of antibodies, the secretion of cytokines, and the increase in $\mathrm{CD}^{4+}$ and $\mathrm{CD}^{8+} \mathrm{T}$ lymphocyte counts in peripheral blood, as well as provided a protective rate of $50 \%$ to the $B$. avium-challenged chickens. The chickens inoculated with the TPPPS adjuvant ompA-DNA vaccine and Freund's adjuvant ompADNA vaccine demonstrated higher levels of immune responses than those inoculated with pure ompA-DNA vaccine, whereas only the ompA-DNA vaccine with $200 \mathrm{mg} / \mathrm{mL}$ TPPPS completely protected the chickens against $B$. avium infection. These findings indicate that the $B$. avium ompA-DNA vaccine combined with TPPPS is a potentially effective $B$. avium vaccine.

Keywords: Bordetella avium, outer membrane protein A, DNA vaccine, Pinus massoniana pollen polysaccharides, adjuvant, chicken

\section{INTRODUCTION}

Bordetella avium was first isolated from the respiratory tracts of turkeys in 1967 (Filion et al., 1967). B. avium is an acute infectious pathogen that demonstrates high horizontal infectivity and congenital transmissibility, and it mainly infects young chickens and turkeys (Beach et al., 2012). This pathogen has been found in many other avian species, including Muscovy ducks, 
domesticated geese, partridges, ostriches, cockatoos, macaws, parrot finches, and cockatiels (Hinz and Glunder, 1985; Raffel et al., 2002). Widespread dissemination of this pathogen both in wild and domesticated poultry was demonstrated by a serum prevalence survey (Raffel et al., 2002). Harrington et al. (2009) isolated a B. avium strain from patients with respiratory diseases and proved that B. avium is also an opportunistic pathogen in humans. The vaccines that are currently available to prevent $B$. avium disease are mainly live, temperature-sensitive, mutant vaccine, and whole-cell cephalosporins. Although the live vaccines and bacterins of $B$. avium can provide protection to at least 3-week-old turkeys, younger poultry respond poorly to vaccination (Rimler and Kunkle, 1998). Existing vaccines can also offer some protection against severe diseases; however, they do not limit the infection and spread of B. avium (Stockwell et al., 2011). Developing a novel vaccine to prevent B. avium infection is therefore necessary.

Since the first DNA vaccine was reported in 1990 (Wolff et al., 1990), the efficacy of DNA vaccines against infectious diseases have been demonstrated (Robinson et al., 1993; Sun et al., 2010; Borrego et al., 2011). Compared with the traditional inactivated, attenuated, and subunit vaccines, DNA vaccines exhibit more advantages by inducing a broad spectrum of cellular and humoral immune responses. DNA vaccine immunization can prolong the expression of antigens, as well as sustain their activity (Tang et al., 1992; Yankauckas et al., 1993), which represents a novel strategy to prevent or control some infectious diseases. Since DNA vaccines have become popular during the past two decades, this technology has brought both considerable excitement and disappointment. The magnitude of immune responses elicited by DNA vaccines are generally lower in humans and large animals than in small animals, as proven by a number of clinical trials (Laddy and Weiner, 2006). Therefore, further development of DNA vaccines has been limited by their relatively modest immunogenicity. To overcome this deficiency, several strategies have been proposed to enhance the efficacy of DNA vaccines. Among these, applying an adjuvant in vaccination is a good option to improve the immunogenicity of DNA vaccines.

Adjuvants are believed to activate the innate immune system, and thereby enhance the adaptive immune response to a simultaneously administered antigen (O'Hagan and De Gregorio, 2009; Mbow et al., 2010). Investigating novel plant compounds that modulate the immune system have become a promising field of research, particularly in searching for newgeneration vaccine adjuvants (Licciardi and Underwood, 2011). Many polysaccharides, such as Astragalus polysaccharides, Panax ginseng polysaccharides, and Ganoderma lucidum polysaccharide F3, have been demonstrated their immunopotentiating function and adjuvant efficacy (Jiang et al., 2010; Lai et al., 2010; Ma et al., 2010). Notably, pine pollen, a kind of nutritional pollen, which is gloriously known as "King of Pollen" in China, has attracted our attention. The principal pine species in Mount Taishan region is Pinus massoniana, and the polysaccharides extracted from Taishan Pinus massoniana pollen has been studied in our laboratory since 2003, which has been found to be an effective adjuvant for inactivated and subunit vaccines (Wei et al., 2011;
Cui et al., 2013). However, the use of Taishan Pinus massoniana pollen polysaccharides (TPPPS) as an adjuvant of DNA vaccines has not yet been investigated.

In the current study, to develop a novel B. avium vaccine, we constructed a recombinant plasmid expressing B. avium outer membrane protein A (ompA), which is an important component of the outer membrane protein and can induce high antibody titers as a protective antigen (Gentry-Weeks et al., 1992). To improve the immunogenicity of this DNA vaccine, TPPPS was used as an adjuvant for the DNA vaccine to examine its immune conditioning effects. We found that the recombinant ompADNA vaccine induced specific immune responses, although it incompletely protected the chickens against $B$. avium challenge. By contrast, the TPPPS adjuvant elevated the immune effects of the DNA vaccine to resist the B. avium challenge effectively.

\section{MATERIALS AND METHODS}

\section{Ethics Statement}

The animal procedures used in this study were approved by the Animal Care and Use Committee of Shandong Agricultural University (Permit number: 20010510) and performed in accordance with the "Guidelines for Experimental Animals" of the Ministry of Science and Technology (Beijing, China).

\section{Bacterial Strains, Plasmids, and Cells}

Bordetella avium LL strain was isolated in our laboratory in 2008 (Shandong, China). The strain was cultured and maintained in lysogeny broth agar and broth at $37^{\circ} \mathrm{C}$. The eukaryotic expression plasmid pVAX1 was purchased from Invitrogen (Carlsbad, CA, USA). In addition, BHK-21 cells were maintained in minimum essential medium (MEM, GIBCO) that contained 10\% fetal bovine serum (FBS, GIBCO) and $1 \%$ antibiotics (Invitrogen) at $37^{\circ} \mathrm{C}$ in a humidified atmosphere of $5 \% \mathrm{CO}_{2}$.

\section{Construction of Recombinant ompA Plasmid}

The primers were designed according to the ompA gene sequence of B. avium (GenBank accession number: M96550.1) using Primer 5.0. EcoR I and Xho I restriction enzyme sites were introduced into the respective $5^{\prime}$ termini (underlined): forward primer 5'-GCGAATTCCATGAACAAACCCTCCAA A-3 $3^{\prime}$ and reverse primer $5^{\prime}$-CCGCTCGAGTTACTTGCGGCTA CCGACGATT-3'. The polymerase chain reaction (PCR) product was digested with EcoR I and Xho I and cloned into the pVAX1 vector. The resultant plasmid was confirmed by sequencing (Sunny, Shanghai) and then transformed into $\mathrm{DH} 5 \alpha$ competent cells (E. coli) to amplify the yield.

\section{Transfection and Western Blot Analysis}

Confluent BHK-21 cells were cultured in 6-well plates without antibiotics, and recombinant ompA plasmids (4 $\mu \mathrm{g})$ were transfected into the BHK-21 cells using Lipofectamine (Invitrogen). The transfected cells were cultured in MEM with 1\% FBS for $72 \mathrm{~h}$. The expressed ompA in the cell culture supernatants 
was purified through nickel affinity chromatography according to a previous method (Asgarian-Omran et al., 2013) and then verified through Western blot analysis using an anti His-Tag monoclonal antibody (Cwbio, China; Temple et al., 2010).

\section{Vaccine Preparation}

Taishan Pinus massoniana pollen polysaccharides was prepared in our laboratory through water extraction and ethanol precipitation (Wei et al., 2011). The recombinant plasmids in E. coli $\mathrm{DH} 5 \alpha$ were extracted using EndoFree Plasmid Giga Kit (Qiagen). Plasmid concentration was determined using NanoDrop (Thermo). The recombinant plasmids were then mixed with TPPPS or Freund's incomplete adjuvant (Solarbio, Beijing) at a ratio of 1:1 up to a final concentration of $250 \mu \mathrm{g} / \mathrm{mL}$. The contents of TPPPS were set at three doses, namely, 50 (low), 100 (moderate), and 200 (high) $\mathrm{mg} / \mathrm{mL}$, in three separate TPPPS adjuvant vaccines. The recombinant plasmids mixed with three doses of TPPPS and Freund's adjuvant were separately prepared to obtain the corresponding adjuvant DNA vaccines.

\section{Animal Experiment}

A total of 224 one-day-old specific pathogen-free white leghorn chickens (male; Spirax Ferrer Poultry Co., Ltd, Jinan) were randomly separated into seven sterilized isolators, and each isolator contained a group of 32 chickens (groups I-VII). The ambient conditions were set to $20-25^{\circ} \mathrm{C}$ and $30-40 \%$ relative humidity, and the air entering the isolators was filtered.

The chickens in groups I-VII were intramuscularly injected with $0.4 \mathrm{~mL}$ low, moderate, and high doses TPPPS adjuvant ompA-DNA vaccines, Freund's adjuvant ompA-DNA vaccine, pure ompA-DNA vaccine, empty plasmid, and phosphate buffered saline (PBS), respectively, at 1, 7, and 14 days old. Groups I-VII were named OmpA-TPPPS (L), OmpA-TPPPS (M), OmpA-TPPPS (H), OmpA-Freund, OmpA, Empty plasmid, and Mock, respectively. At 7, 14, 21, 28, 35, 42, and 49 days post the first inoculation (dpi), three chickens from each group were selected randomly to determine the antibody, IFN- $\gamma$, IL2 , and IL-4 concentrations in serum, as well as the $\mathrm{CD}^{4+}$ and $\mathrm{CD}^{8+} \mathrm{T}$ lymphocytes counts in peripheral blood. The animals were starved for $12 \mathrm{~h}$ before sampling.

One week after the third inoculation (21 dpi), 20 chickens in each group (including nine sampled and 11 unsampled chickens) were placed into a new isolator and then challenged intraperitoneally with 10 median lethal dose $\left(\mathrm{LD}_{50}\right)$ B. avium $\mathrm{LL}$ strain. Clinical symptoms, including labored breathing, sneezing, and oculonasal discharges, were monitored for 7 days after challenge. The protective rate in each group were calculated according to the following formulas:

Protective rate $(\%)=\frac{\text { No. of chickens without clinical symptoms }}{\text { Total No. } \times 100 \%}$.

\section{Detection of Serum Antibody Titers, IFN- $\gamma$, IL-2, and IL-4}

Three serum samples from each group were randomly collected during sampling. The serum antibody titers were detected via enzyme-linked immunosorbent assay (ELISA) as described previously (Li et al., 2012). In addition, the cytokines of IFN- $\gamma$, IL-2, and IL-4 were detected using the chicken IFN- $\gamma$, IL-2, and IL-4 ELISA kits (Langdon Bio-technology Co., Ltd, Shanghai), respectively. The absorbance at $450 \mathrm{~nm}$ was measured using an ELISA reader.

\section{Detection of $\mathrm{CD}^{4+}$ and $\mathrm{CD}^{8+} \mathrm{T}$ Lymphocytes in Peripheral Blood}

Fresh, anticoagulant-treated peripheral blood samples from three chickens in each group were randomly collected and separately mixed with an equivalent volume of PBS. Then, $2 \mathrm{~mL}$ of the mixture was added into $3 \mathrm{~mL}$ lymphocyte separation medium (Solarbio, China), which was centrifuged at $2000 \mathrm{rpm}$ for $15 \mathrm{~min}$. The lymphocytes were harvested and washed twice with PBS. $\mathrm{CD}^{4+}$ dye $(10 \mu \mathrm{L}$, Mouse Anti-chicken CD4-FITC, Cat: 8210-02, Lot: H4809-MM62, USA) and $\mathrm{CD}^{8+}$ dye $(10 \mu \mathrm{L}$, Mouse Antichicken CD8-RPE, Cat: 8220-09, Lot: G149-VJ39K, USA) were added into $50 \mu \mathrm{L}$ lymphocyte suspension. The suspension was incubated at $4^{\circ} \mathrm{C}$ for $20 \mathrm{~min}$. The percentages of $\mathrm{CD}^{4+}$ and $\mathrm{CD}^{8+}$ $\mathrm{T}$ lymphocytes were detected via flow cytometry (Guaga Easy Cyte Mini, USA).

\section{Statistical Analysis}

Data were presented as mean \pm standard deviation (SD), and Duncan's multiple-range test was performed to analyze the differences among groups using SPSS 17.0 software. A $P$-value of $<0.05$ was considered statistically significant.

\section{RESULTS}

\section{Construction and Expression of Recombinant ompA Plasmid}

Firstly, the ompA gene of B. avium was amplified by PCR, and agarose gel electrophoresis showed that the size of the amplified ompA PCR products was $597 \mathrm{bp}$, which was consistent with the expected ompA fragment size. Then the PCR products were cloned into the pVAX1 vector, and the recombinant plasmid was verified through restriction digestion and sequencing (data not shown). After transfection into the BHK-21 cells, the target recombinant protein was purified via nickel affinity chromatography based on the presence of $6 \times$ His tag in the fusion protein. The contaminant proteins were washed with buffer with $20 \mathrm{mM}$ imidazole, and the target protein was eluted with buffer that contained $0.5 \mathrm{M}$ imidazole. The protein fractions were analyzed via SDS-PAGE and Western blot analysis, and the results showed that a single protein band with an apparent molecular weight of $27 \mathrm{kDa}$ was obtained after purification (Figure 1).

\section{Changes in Serum Antibody Titers}

The levels of antibody induced by vaccination are the key to examining the effects of vaccines. The dynamic changes in the serum antibody titers in each group are presented in Figure 2. At $14 \mathrm{dpi}$, the serum antibody titers in groups OmpA-TPPPS (L), (M), (H), OmpA-Freund, and OmpA increased and were 


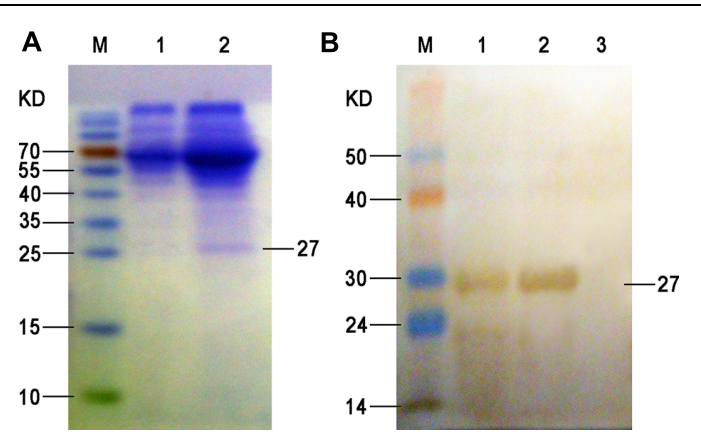

FIGURE 1 | SDS-PAGE (A) and Western blot (B) of the expressed ompA in the supernatant. (A) M, protein molecular weight markers; lane 1, proteins isolated from the culture supernatant of BHK-21 cells at $72 \mathrm{~h}$ after empty plasmid transfection (negative control); lane 2, proteins isolated from the culture supernatant of BHK-21 cells at $72 \mathrm{~h}$ after pVAX1-ompA plasmid transfection. (B) M, PageRuler prestained protein ladder; 1, proteins isolated from the culture supernatant of BHK-21 cells at $72 \mathrm{~h}$ after pVAX1-ompA plasmid transfection; 2, purified recombinant protein from eluted fraction; 3 , proteins isolated from the culture supernatant of BHK-21 cells at $72 \mathrm{~h}$ after empty plasmid transfection (negative control).

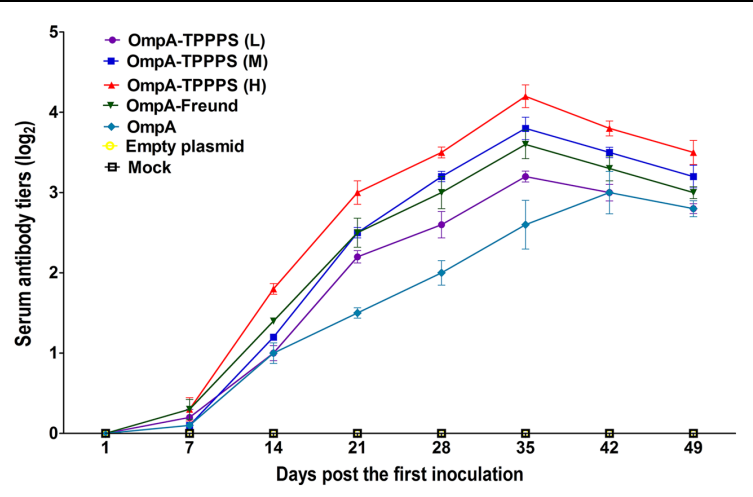

FIGURE 2 | Changes in the serum antibody titers of the chickens inoculated with vaccines. Chickens in the seven groups were inoculated with 50 (purple), 100 (blue), and 200 (red) mg/mL of TPPPS adjuvant ompA-DNA vaccines, Freund's adjuvant ompA-DNA vaccine (green), pure ompA-DNA vaccine (cyan), empty plasmid (yellow), and PBS (black), respectively, at 1, 7, and 14 days old. Serum was collected at 7, 14, 21, 28, 35, 42, and 49 dpi. The antibody titers were then determined via indirect ELISA. All values shown are the means \pm SD of three independent experiments.

significantly higher than those in groups Empty plasmid and Mock $(P<0.05)$. Notably, the serum antibody titers in group OmpA-TPPPS $(\mathrm{H})$ were significantly higher than those in other groups $(P<0.05)$ at $14-49 \mathrm{dpi}$. At $35 \mathrm{dpi}$, the serum antibody titers in groups OmpA-TPPPS (L), (M), (H), and OmpA-Freund reached their peak value and were higher than those in group OmpA. However, the antibody titers in group OmpA peaked at 42 dpi.

\section{Changes in Serum IFN- $\gamma$, IL-2, and IL-4}

Cytokines are crucial in fighting off infections and are involved in immune responses (Lowry, 1993). The results of serum IFN- $\gamma$,
IL-2, and IL-4 concentrations are shown in Figure 3. As shown in Figures $\mathbf{3 A}, \mathbf{B}$, the serum IFN- $\gamma$ and IL-2 concentrations were significantly higher in group OmpA than in groups Empty plasmid and Mock $(P<0.05)$. Moreover, the concentrations of these two cytokines were significantly higher in groups OmpATPPPS (L), (M), (H), and OmpA-Freund than in group OmpA $(P<0.05)$, and these two indicators were significantly higher in group OmpA-TPPPS $(\mathrm{H})$ than in other groups $(P<0.05)$. As shown in Figure 3C, the concentrations of serum IL4 in group OmpA-TPPPS $(\mathrm{H})$ were significantly higher than in other groups $(P<0.05)$. The overall IL-4 concentrations in groups OmpA-TPPPS (L), (M), (H), and OmpA-Freund were also significantly higher than in groups OmpA, Empty plasmid, and Mock $(P<0.05)$. A comparison between group OmpA and groups Empty plasmid and Mock indicated that the serum IL-4 concentrations were higher in group OmpA than in groups Empty plasmid and Mock, although the disparity was insignificant $(P>0.05)$.

\section{Changes in $\mathrm{CD}^{4+}$ and $\mathrm{CD}^{8+} \mathrm{T}$ Lymphocyte Counts in the Peripheral Blood}

$\mathrm{CD}^{4+}$ and $\mathrm{CD}^{8+} \mathrm{T}$ lymphocyte counts directly reflect immune function in animals (Torti et al., 2012). Tables 1 and 2 show the percentages of $\mathrm{CD}^{4+}$ and $\mathrm{CD}^{8+} \mathrm{T}$ lymphocytes in the peripheral blood, respectively, where the percentages of $\mathrm{CD}^{4+}$ and $\mathrm{CD}^{8+} \mathrm{T}$ lymphocytes were significantly higher in group OmpA than in groups Empty plasmid and Mock $(P<0.05)$. Moreover, the percentages of $\mathrm{CD}^{4+}$ and $\mathrm{CD}^{8+} \mathrm{T}$ lymphocytes in groups OmpA-TPPPS (L), (M), (H), and OmpA-Freund were significantly higher than those in group OmpA $(P<0.05)$. Notably, The percentages of $\mathrm{CD}^{4+}$ and $\mathrm{CD}^{8+} \mathrm{T}$ lymphocytes were also significantly higher in group OmpA-TPPPS $(\mathrm{H})$ than in other groups $(P<0.05)$.

\section{Protective Effects of the Vaccines}

To evaluate the protective effects of the ompA-DNA vaccine against $B$. avium infection, we challenged 20 chickens from each group with $10 \mathrm{LD}_{50}$ B. avium LL strain at 1 week post the third inoculation. Clinical symptoms were monitored daily, and the protective rates of different groups were calculated as described in the section "Materials and Methods" (Figure 4). The result showed that the morbidity was significantly lower in chickens inoculated with the ompA-DNA vaccine than in chickens in the groups Empty plasmid and Mock $(P<0.05)$. In addition, the protective rate in group OmpA-TPPPS $(\mathrm{H})$ was significantly higher than those in other groups $(P<0.05)$. These data demonstrated that the pure ompA-DNA vaccine could protect the chickens against B. avium infection at a rate of $50 \%$, and the ompA-DNA vaccine with $200 \mathrm{mg} / \mathrm{mL}$ TPPPS completely protected the chickens against $B$. avium infection.

\section{DISCUSSION}

Bordetella avium is the causative agent of a highly contagious upper respiratory disease in young poultry, and existing 

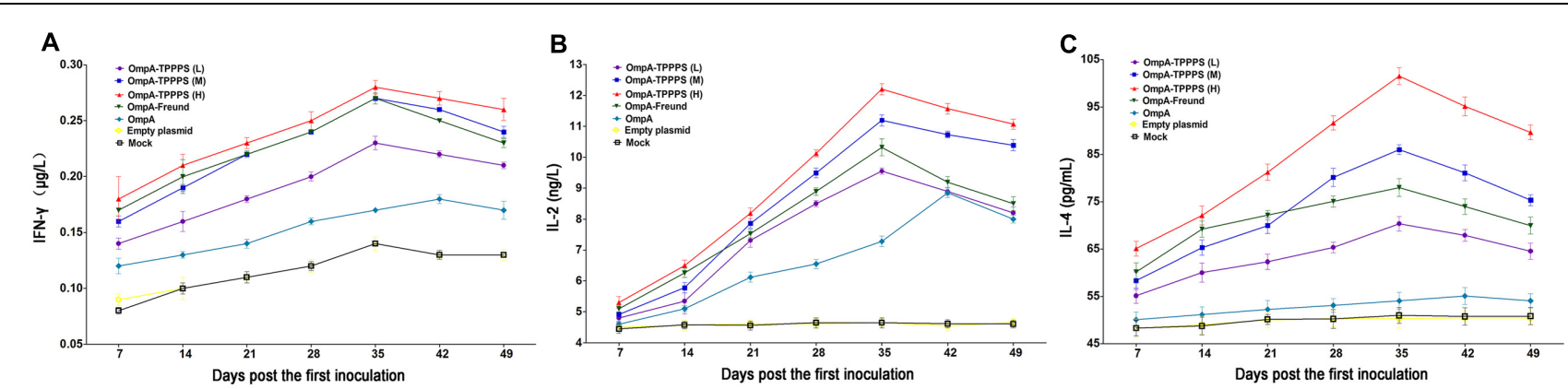

FIGURE 3 | Changes in cytokines in the chickens inoculated with vaccines. Chickens in the seven groups were inoculated with 50 (purple), 100 (blue), and 200 (red) mg/mL of TPPPS adjuvant ompA-DNA vaccines, Freund's adjuvant ompA-DNA vaccine (green), pure ompA-DNA vaccine (cyan), empty plasmid (yellow), and PBS (black), respectively, at 1, 7, and 14 days old. Serum was collected at 7, 14, 21, 28, 35, 42 , and 49 dpi. IFN- $\gamma$ (A), IL-2 (B), and IL-4 (C) were detected using the chicken IFN- $\gamma$, IL-2, and IL-4 ELISA kits. All values shown are the means \pm SD of three independent experiments.

vaccines provide limited protection only. In this study, we constructed a recombinant plasmid that expressed B. avium ompA, which was used to prepare a novel B. avium DNA vaccine. In addition, TPPPS was used as the adjuvant of this DNA vaccine, and its immune conditioning effects were examined. We determined that the pure ompA-DNA vaccine induced specific immune responses and protected the chickens, which displayed a $50 \%$ protective rate. By contrast, the TPPPS adjuvant ompA-DNA vaccine elicited remarkably higher levels of serum antibody titers, cytokines, and $\mathrm{T}$ lymphocyte counts, as well as caused higher protective rates among the chickens.

TABLE 1 | Changes of $C D^{4+} \mathrm{T}$ lymphocyte counts in peripheral blood.

\begin{tabular}{|c|c|c|c|c|c|c|c|}
\hline \multirow[t]{2}{*}{ Group* } & \multicolumn{7}{|c|}{ Days post the first inoculation (d) } \\
\hline & 7 & 14 & 21 & 28 & 35 & 42 & 49 \\
\hline OmpA-TPPPS (L) & $7.26 \pm 0.83^{a}$ & $8.81 \pm 0.61^{a}$ & $11.33 \pm 0.63^{a}$ & $13.25 \pm 1.13^{\mathrm{a}}$ & $14.49 \pm 0.42^{\mathrm{a}}$ & $15.76 \pm 0.35^{a}$ & $14.67 \pm 1.02^{\mathrm{a}}$ \\
\hline OmpA-TPPPS (M) & $9.11 \pm 0.93^{b}$ & $12.44 \pm 0.81^{b}$ & $15.84 \pm 0.78^{b}$ & $17.45 \pm 0.99^{b}$ & $18.33 \pm 0.79^{b}$ & $20.26 \pm 0.85^{b}$ & $17.65 \pm 0.74^{b}$ \\
\hline OmpA-TPPPS $(\mathrm{H})$ & $11.70 \pm 0.06^{c}$ & $15.38 \pm 0.45^{\mathrm{C}}$ & $18.83 \pm 0.47^{c}$ & $22.04 \pm 0.49^{c}$ & $24.29 \pm 0.67^{c}$ & $27.98 \pm 1.05^{\mathrm{C}}$ & $25.32 \pm 0.80^{c}$ \\
\hline OmpA-Freund & $9.84 \pm 0.41^{\mathrm{b}}$ & $13.00 \pm 0.80^{b}$ & $15.59 \pm 0.79^{b}$ & $18.00 \pm 0.90^{b}$ & $18.66 \pm 0.11^{b}$ & $19.59 \pm 0.62^{b}$ & $17.00 \pm 0.80^{b}$ \\
\hline OmpA & $5.00 \pm 0.90^{d}$ & $6.26 \pm 0.86^{d}$ & $8.18 \pm 0.75^{d}$ & $10.36 \pm 0.79^{d}$ & $11.28 \pm 0.10^{d}$ & $12.30 \pm 0.10^{d}$ & $10.01 \pm 0.69^{d}$ \\
\hline Empty plasmid & $4.40 \pm 0.60^{d}$ & $5.00 \pm 0.10^{\mathrm{e}}$ & $6.00 \pm 0.90^{e}$ & $7.37 \pm 0.15^{\mathrm{e}}$ & $6.99 \pm 0.55^{\mathrm{e}}$ & $7.24 \pm 0.70^{e}$ & $6.72 \pm 0.24^{\mathrm{e}}$ \\
\hline Mock & $4.30 \pm 0.30^{d}$ & $5.00 \pm 0.40^{e}$ & $5.00 \pm 0.50^{e}$ & $7.41 \pm 0.71^{\mathrm{e}}$ & $6.52 \pm 0.42^{\mathrm{e}}$ & $6.38 \pm 0.13^{e}$ & $6.44 \pm 0.11^{\mathrm{e}}$ \\
\hline
\end{tabular}

*Group names represent that chickens in these groups were inoculated with 50, 100, and $200 \mathrm{mg} / \mathrm{mL}$ of TPPPS adjuvant ompA-DNA vaccines, Freund's adjuvant ompA-DNA vaccine, pure ompA vaccine, empty plasmid, and PBS, respectively.

${ }^{\#} \mathrm{CD}^{4+}$ T lymphocyte counts in the same column are compared by Duncan's multiple-range tests. Different lowercase letter superscripts indicate significant differences $(P<0.05)$. Data are expressed as mean percentage $\pm S D$.

TABLE 2 | Changes of $C^{8+} \mathrm{T}$ lymphocyte counts in peripheral blood.

\begin{tabular}{|c|c|c|c|c|c|c|c|}
\hline \multirow[t]{2}{*}{ Group* } & \multicolumn{7}{|c|}{ Days post the first inoculation (d) } \\
\hline & 7 & 14 & 21 & 28 & 35 & 42 & 49 \\
\hline OmpA-TPPPS (L) & $5.56 \pm 0.86^{a}$ & $7.23 \pm 0.21^{a}$ & $9.26 \pm 0.69^{a}$ & $10.26 \pm 0.55^{a}$ & $11.18 \pm 0.33^{a}$ & $13.31 \pm 0.38^{a}$ & $12.01 \pm 0.12^{a}$ \\
\hline OmpA-TPPPS (M) & $7.03 \pm 0.20^{b}$ & $8.00 \pm 0.55^{a}$ & $10.60 \pm 0.35^{b}$ & $12.00 \pm 0.50^{b}$ & $14.00 \pm 0.70^{b}$ & $16.03 \pm 0.35^{\mathrm{b}}$ & $14.87 \pm 0.61^{b}$ \\
\hline OmpA-TPPPS $(\mathrm{H})$ & $8.03 \pm 0.45^{c}$ & $10.00 \pm 0.40^{b}$ & $12.29 \pm 0.27^{c}$ & $14.10 \pm 0.38^{c}$ & $16.37 \pm 0.75^{\mathrm{c}}$ & $17.94 \pm 0.83^{c}$ & $16.82 \pm 0.87^{\circ}$ \\
\hline OmpA-Freund & $7.97 \pm 0.25^{c}$ & $9.00 \pm 0.60^{c}$ & $11.00 \pm 0.90^{b}$ & $12.93 \pm 0.40^{b}$ & $14.00 \pm 0.30^{b}$ & $15.00 \pm 0.50^{d}$ & $13.10 \pm 0.10^{\circ}$ \\
\hline OmpA & $4.99 \pm 0.02^{a}$ & $5.98 \pm 0.90^{d}$ & $6.66 \pm 0.87^{d}$ & $7.95 \pm 0.83^{d}$ & $9.00 \pm 0.50^{d}$ & $11.00 \pm 0.60^{e}$ & $8.02 \pm 0.67^{e}$ \\
\hline Empty plasmid & $4.18 \pm 0.35^{d}$ & $4.96 \pm 0.44^{\mathrm{e}}$ & $5.39 \pm 0.30^{e}$ & $5.96 \pm 0.48^{\mathrm{e}}$ & $5.75 \pm 0.40^{e}$ & $5.38 \pm 0.39^{f}$ & $5.65 \pm 0.48^{f}$ \\
\hline Mock & $4.23 \pm 0.32^{d}$ & $4.70 \pm 0.34^{e}$ & $5.42 \pm 0.42^{\mathrm{e}}$ & $5.94 \pm 0.48^{e}$ & $5.78 \pm 0.36^{e}$ & $5.58 \pm 0.38^{f}$ & $5.58 \pm 0.02^{f}$ \\
\hline
\end{tabular}

*Group names represent that chickens in these groups were inoculated with 50, 100, and $200 \mathrm{mg} / \mathrm{mL}$ of TPPPS adjuvant ompA-DNA vaccines, Freund's adjuvant ompA-DNA vaccine, pure ompA vaccine, empty plasmid, and PBS, respectively.

${ }^{\#} C D^{8+} T$ lymphocyte counts in the same column are compared by Duncan's multiple-range tests. Different lowercase letter superscripts indicate significant differences $(P<0.05)$. Data are expressed as mean percentage $\pm S D$. 


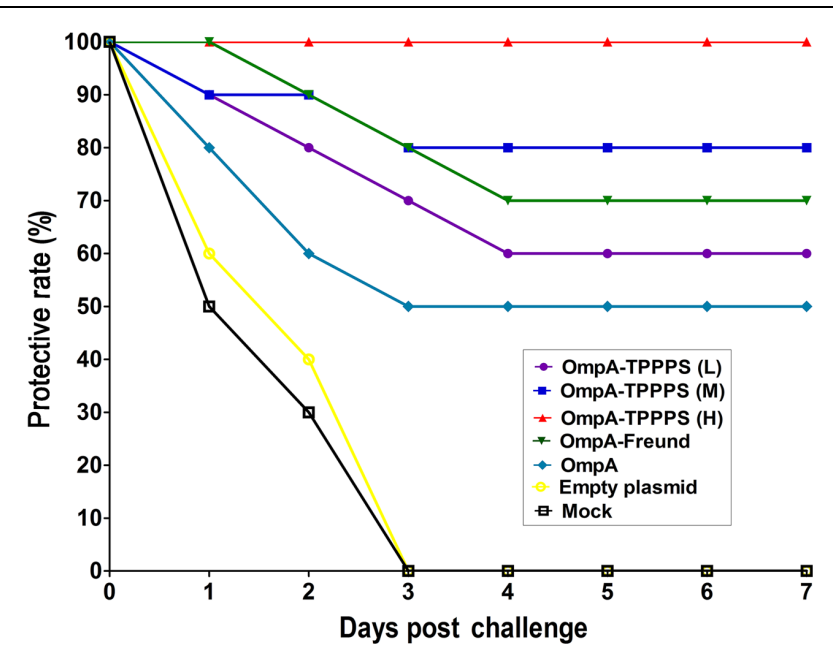

FIGURE 4 | Protective rates of $B$. avium-challenged chickens. Chickens in the seven groups were inoculated with 50 (purple), 100 (blue), and 200 (red) mg/mL of TPPPS adjuvant ompA-DNA vaccines, Freund's adjuvant ompA-DNA vaccine (green), pure ompA-DNA vaccine (cyan), empty plasmid (yellow), and PBS (black), respectively, at 1, 7, and 14 days old. One week after the third inoculation, 20 chickens from each group were challenged intraperitoneally with $10 L_{50}$ B. avium LL strain. Clinical symptoms, including labored breathing, sneezing, and oculonasal discharges, were monitored for seven successive days after the challenge.

DNA vaccine, also known as nucleic acid vaccine, is a new research field that has been developed in the research of gene therapy in recent years. DNA vaccine can express antigen protein via eukaryotic expression pattern when it is absorbed by the host cells; the sustained expression can induce a strong and lasting immune response in vertebrates. In this study, the natural ompA of B. avium is a prokaryotic protein, and its molecular structure may become more complex when it is expressed in the eukaryotic expression system. Thus, some epitopes may be altered or hidden. However, our results have proven that the ompA expressed in host cells also provided a certain immune protection, thereby indicating that it retained certain epitopes and immunogenicity of natural ompA. Moreover, we found that the addition of TPPPS adjuvant remarkably improved the immune protective effects of ompA-DNA vaccine. This result further verified the specific antigenicity of ompA and implied the immunoregulatory activity of TPPPS.

DNA vaccine offers distinctive advantages compared with traditional vaccines. This type of vaccine promotes the expression of specific antigens in host cells and elicits both humoral and cellular immune responses. In addition, it is easy to produce, relatively inexpensive, homogeneous and heat stable (Belakova et al., 2007). However, given that the immune response of DNA vaccines depends on several parameters, such as the selection of the candidate antigen, vaccine vector, adjuvant type, and administration route (Oran and Robinson, 2003; Perrie et al., 2003; Sasaki et al., 2003; Liu, 2011), all of these factors may possibly influence the effects of vaccination. The safety of using vaccine vectors in animals is a primary consideration.
This study employed the pVAX1 plasmid, the use of which was approved by the US Food and Drug Administration ("Points to Consider on Plasmid DNA Vaccines for Preventive Infectious Disease Indications," published on December 22, 1996, Docket No. 96N-0400). To date, the pVAX1 plasmid is the safest vector in DNA vaccine, because it demonstrates minimal possibility of chromosomal integration and is less likely to elicit allergic responses. Studies have reported that pure pVAX1 plasmid does not exert any negative effect on animals and does not interfere with the efficacy of DNA vaccines (Song et al., 2009, 2010), which is consistent with our results. Moreover, we chose traditional intramuscular injection as the inoculation method in our animal experiment. Some studies, however, have shown that inoculation via electroporation can enhance plasmid uptake and immune responses (BodlesBrakhop and Draghia-Akli, 2008). Many novel DNA delivery systems have also been invented, including gene gun and synthetic delivery systems. Thus, further studies must investigate the effects of the ompA-DNA vaccine using novel delivery systems.

Two types of T helper (Th) clones (Th1 and Th2 cells) differ in cytokine secretion patterns and in other functions (Mosmann et al., 1986). The major cytokines associated with the Th1 cell subsets are IL-2, TNF- $\alpha$, and IFN- $\gamma$, which can enhance Tc cellular cytotoxicity and cell-mediated immune responses. The Th2 cell subsets secrete IL-4, IL-5, and IL-10, and these cytokines mainly promote antibody production and mediate humoral immune responses. We observed that the ompADNA vaccine significantly enhanced the production of IFN- $\gamma$ and IL-2, but not IL-4, which indicated that the ompA-DNA vaccine mainly induced Th1 immune response. In antibacterial defense, these Th1 cytokines may enhance the proliferation and differentiation of lymphocytes and bactericidal activities of the innate immune cells, such as nature killer cells and macrophages.

Adjuvants are widely applied to improve the immunogenicity of subunit virus-like particles and DNA vaccines (Buonaguro et al., 2011). Various plant polysaccharides, such as Astragalus, Panax ginseng, and Taishan Robinia pseudoacacia polysaccharides, cannot only activate immunocytes but can also improve cytokine secretion (Jiang et al., 2010; Ma et al., 2010; Zhang et al., 2014). They also activate complement and reticuloendothelial systems, thereby regulating the immunologic function of organisms (Currier et al., 2003; Lai et al., 2010). Moreover, plant polysaccharides are typically less immunogenic, non-toxic, and biodegradable, and thus, are considered novel natural immune potentiator. Our previous studies have revealed that TPPPS can significantly strengthen immune response and enhance the effects of vaccines (Wei et al., 2011; Cui et al., 2013). In addition, TPPPS is water-soluble and exhibits high hydrophilicity and viscidity, which are suitable properties for an adjuvant (Wei et al., 2011). The present study showed that the chickens inoculated with the TPPPS adjuvant ompA-DNA vaccine displayed higher immunity and protective rate than those inoculated with the pure ompA-DNA vaccine. Notably, the $200 \mathrm{mg} / \mathrm{mL}$ TPPPS exhibited the best capability to improve the effects of the ompA-DNA vaccine. TPPPS also shortened 
the time before antibody levels peaked. Therefore, TPPPS is a potential vaccine adjuvant.

\section{CONCLUSION}

This study demonstrated that the ompA-DNA vaccine induced both humoral and cellular immune responses (particularly the Th1 type). TPPPS, which was used as the adjuvant, effectively improved the immunogenicity of DNA vaccine, including antibody production, cytokine secretion, lymphocyte differentiation, and protective rate. The results of this study indicated the potential of the $B$. avium ompA-DNA vaccine combined with TPPPS adjuvant in preventing $B$. avium infection.

\section{REFERENCES}

Asgarian-Omran, H., Amirzargar, A. A., Arjmand, M., Eshraghian, M., Nikbin, B., Eshraghi, S., et al. (2013). Expression, purification and characterization of three overlapping immunodominant recombinant fragments from Bordetella pertussis filamentous hemagglutinin. Avicenna J. Med. Biotechnol. 5, 20-28.

Beach, N. M., Thompson, S., Mutnick, R., Brown, L., Kettig, G., Puffenbarger, R., et al. (2012). Bordetella avium antibiotic resistance, novel enrichment culture, and antigenic characterization. Vet. Microbiol. 160, 189-196. doi: 10.1016/j.vetmic.2012.05.026

Belakova, J., Horynova, M., Krupka, M., Weigl, E., and Raska, M. (2007). DNA vaccines: are they still just a powerful tool for the future? Arch. Immunol. Ther. Exp. (Warsz) 55, 387-398. doi: 10.1007/s00005-007-0044-4

Bodles-Brakhop, A. M., and Draghia-Akli, R. (2008). DNA vaccination and gene therapy: optimization and delivery for cancer therapy. Expert. Rev. Vaccines 7 , 1085-1101. doi: 10.1586/14760584.7.7.1085

Borrego, B., Argilaguet, J. M., Perez-Martin, E., Dominguez, J., Perez-Filgueira, M., Escribano, J. M., et al. (2011). A DNA vaccine encoding foot-and-mouth disease virus B and T-cell epitopes targeted to class II swine leukocyte antigens protects pigs against viral challenge. Antiviral Res. 92, 359-363. doi: 10.1016/j.antiviral.2011.07.017

Buonaguro, F. M., Tornesello, M. L., and Buonaguro, L. (2011). New adjuvants in evolving vaccine strategies. Expert. Opin. Biol. Ther. 11, 827-832. doi: $10.1517 / 14712598.2011 .587802$

Cui, G., Zhong, S., Yang, S., Zuo, X., Liang, M., Sun, J., et al. (2013). Effects of Taishan Pinus massoniana pollen polysaccharide on the subunit vaccine of Proteus mirabilis in birds. Int. J. Biol. Macromol. 56, 94-98. doi: 10.1016/j.ijbiomac.2013.02.006

Currier, N. L., Lejtenyi, D., and Miller, S. C. (2003). Effect over time of invivo administration of the polysaccharide arabinogalactan on immune and hemopoietic cell lineages in murine spleen and bone marrow. Phytomedicine 10, 145-153. doi: 10.1078/094471103321659852

Filion, R., Cloutier, S., Vrancken, E. R., and Bernier, G. (1967). Respiratory infection in the turkey caused by a bacterium related to Bordetella bronchiseptica. Can. J. Comp. Med. Vet. Sci. 31, 129-134.

Gentry-Weeks, C. R., Hultsch, A.-L., Kelly, S. M., Keith, J. M., and Curtiss, R. (1992). Cloning and sequencing of a gene encoding a 21-kilodalton outer membrane protein from Bordetella avium and expression of the gene in Salmonella typhimurium. J. Bacteriol. 174, 7729-7742.

Harrington, A. T., Castellanos, J. A., Ziedalski, T. M., Clarridge, J. E. III, and Cookson, B. T. (2009). Isolation of Bordetella avium and novel Bordetella strain from patients with respiratory disease. Emerg. Infect. Dis. 15, 72-74. doi: 10.3201/eid1501.071677

Hinz, K. H., and Glunder, G. (1985). Occurrence of Bordetella avium sp. nov. and Bordetella bronchiseptica in birds. Berl. Munch. Tierarztl. Wochenschr. 98, 369-373.

Jiang, J., Wu, C., Gao, H., Song, J., and Li, H. (2010). Effects of astragalus polysaccharides on immunologic function of erythrocyte in chickens infected with infectious bursa disease virus. Vaccine 28, 5614-5616. doi: 10.1016/j.vaccine.2010.06.025

\section{AUTHOR CONTRIBUTIONS}

RZ, KW, FZ, XL, and ZS designed research; FZ, XL, CY, LL, SY, and $\mathrm{BL}$ performed research; FZ, XL, ZS, KW, and RZ analyzed data; FZ, XL, KW, and RZ wrote the paper.

\section{ACKNOWLEDGMENTS}

The project was supported by the National Science Foundation of China (No. 31272595, 81541165), the Science and Technology Development Plan of Shan dong Province (No. 2012GNC11020), and the Chinese Medicine Antiviral Collaborative Innovation Center of Shandong Province Colleges (No. XTCX2014B0108).

Laddy, D. J., and Weiner, D. B. (2006). From plasmids to protection: a review of DNA vaccines against infectious diseases. Int. Rev. Immunol. 25, 99-123. doi: 10.1080/08830180600785827

Lai, C. Y., Hung, J. T., Lin, H. H., Yu, A. L., Chen, S. H., Tsai, Y. C., et al. (2010). Immunomodulatory and adjuvant activities of a polysaccharide extract of Ganoderma lucidum in vivo and in vitro. Vaccine 28, 4945-4954. doi: 10.1016/j.vaccine.2010.05.037

Li, K., Gao, H., Gao, L., Qi, X., Gao, Y., Qin, L., et al. (2012). Development of an indirect ELISA for serological detection of reticuloendotheliosis virus using the gp90 protein expressed in Pichia pastoris. J. Virol. Methods 180, 43-48. doi: 10.1016/j.jviromet.2011.12.008

Licciardi, P. V., and Underwood, J. R. (2011). Plant-derived medicines: a novel class of immunological adjuvants. Int. Immunopharmacol. 11, 390-398. doi: 10.1016/j.intimp.2010.10.014

Liu, M. A. (2011). DNA vaccines: an historical perspective and view to the future. Immunol. Rev. 239, 62-84. doi: 10.1111/j.1600-065X.2010.00980.x

Lowry, S. F. (1993). Cytokine mediators of immunity and inflammation. Arch. Surg. 128, 1235-1241. doi: 10.1001/archsurg.1993.01420230063010

Ma, X., Guo, Z., Wang, D., Hu, Y., and Shen, Z. (2010). Effects of sulfated polysaccharides and their prescriptions on immune response of ND vaccine in chicken. Carbohydr. Polym. 82, 9-13. doi: 10.1016/j.carbpol.2010.04.013

Mbow, M. L., De Gregorio, E., Valiante, N. M., and Rappuoli, R. (2010). New adjuvants for human vaccines. Curr. Opin. Immunol. 22, 411-416. doi: 10.1016/j.coi.2010.04.004

Mosmann, T. R., Cherwinski, H., Bond, M. W., Giedlin, M. A., and Coffman, R. L. (1986). Two types of murine helper T cell clone. I. Definition according to profiles of lymphokine activities and secreted proteins. J. Immunol. 136, 2348-2357.

O'Hagan, D. T., and De Gregorio, E. (2009). The path to a successful vaccine adjuvant-'the long and winding road'. Drug Discov. Today 14, 541-551. doi: 10.1016/j.drudis.2009.02.009

Oran, A. E., and Robinson, H. L. (2003). DNA vaccines, combining form of antigen and method of delivery to raise a spectrum of IFN-gamma and IL-4-producing $\mathrm{CD}^{4+}$ and $\mathrm{CD}^{8+} \mathrm{T}$ cells. J. Immunol. 171, 1999-2005. doi: 10.4049/jimmunol.171.4.1999

Perrie, Y., McNeil, S., and Vangala, A. (2003). Liposome-mediated DNA immunisation via the subcutaneous route. J. Drug Target 11, 555-563. doi: 10.1080/10611860410001670071

Raffel, T. R., Register, K. B., Marks, S. A., and Temple, L. (2002). Prevalence of Bordetella avium infection in selected wild and domesticated birds in the eastern USA. J. Wildl. Dis. 38, 40-46. doi: 10.7589/0090-3558-38.1.40

Rimler, R. B., and Kunkle, R. A. (1998). Bacterin-induced protection of turkeys against fowl cholera following infection with Bordetella avium. Avian. Dis. 42, 752-756. doi: 10.2307/1592711

Robinson, H. L., Hunt, L. A., and Webster, R. G. (1993). Protection against a lethal influenza virus challenge by immunization with a haemagglutinin-expressing plasmid DNA. Vaccine 11, 957-960. doi: 10.1016/0264-410X(93)90385-B

Sasaki, S., Takeshita, F., Xin, K. Q., Ishii, N., and Okuda, K. (2003). Adjuvant formulations and delivery systems for DNA vaccines. Methods 31, 243-254. doi: 10.1016/S1046-2023(03)00140-3 
Song, H., Yan, R., Xu, L., Song, X., Shah, M. A., Zhu, H., et al. (2010). Efficacy of DNA vaccines carrying Eimeria acervulina lactate dehydrogenase antigen gene against coccidiosis. Exp. Parasitol. 126, 224-231. doi: 10.1016/j.exppara.2010.05.015

Song, X., Xu, L., Yan, R., Huang, X., Shah, M. A., and Li, X. (2009). The optimal immunization procedure of DNA vaccine pcDNA-TA4-IL2 of Eimeria tenella and its cross-immunity to Eimeria necatrix and Eimeria acervulina. Vet. Parasitol. 159, 30-36. doi: 10.1016/j.vetpar.2008. 10.015

Stockwell, S., Kuzmiak-Ngiam, H., Beach, N., Miyamoto, D., Fernandez, R., and Temple, L. (2011). The autotransporter protein from Bordetella avium, Baal, is involved in host cell attachment. Microbiol. Res. 167, 55-60. doi: 10.1016/j.micres.2011.04.003

Sun, Y., Hu, Y. H., Liu, C. S., and Sun, L. (2010). Construction and analysis of an experimental Streptococcus iniae DNA vaccine. Vaccine 28, 3905-3912. doi: 10.1016/j.vaccine.2010.03.071

Tang, D.-C., DeVit, M., and Johnston, S. A. (1992). Genetic immunization is a simple method for eliciting an immune response. Nature 356, 152-154. doi: 10.1038/356152a0

Temple, L. M., Miyamoto, D. M., Mehta, M., Capitini, C. M., Von Stetina, S., Barnes, H. J., et al. (2010). Identification and characterization of two Bordetella avium gene products required for hemagglutination. Infect. Immun. 78, 2370-2376. doi: 10.1128/IAI.00140-10

Torti, C., Prosperi, M., Motta, D., Digiambenedetto, S., Maggiolo, F., Paraninfo, G., et al. (2012). Factors influencing the normalization of $\mathrm{CD}^{4+} \mathrm{T}$-cell count, percentage and $\mathrm{CD}^{4+} / \mathrm{CD}^{8+} \mathrm{T}$-cell ratio in HIV-infected patients on longterm suppressive antiretroviral therapy. Clin. Microbiol. Infect. 18, 449-458. doi: 10.1111/j.1469-0691.2011.03650.x
Wei, K., Sun, Z., Yan, Z., Tan, Y., Wang, H., Zhu, X., et al. (2011). Effects of Taishan Pinus massoniana pollen polysaccharide on immune response of rabbit haemorrhagic disease tissue inactivated vaccine and on production performance of Rex rabbits. Vaccine 29, 2530-2536. doi: 10.1111/j.14690691.2011.03650.x

Wolff, J. A., Malone, R. W., Williams, P., Chong, W., Acsadi, G., Jani, A., et al. (1990). Direct gene transfer into mouse muscle in vivo. Science 247, 1465-1468. doi: 10.1126/science.1690918

Yankauckas, M. A., Morrow, J. E., Parker, S. E., Abai, A., Rhodes, G. H., Dwarki, V. J., et al. (1993). Long-term anti-nucleoprotein cellular and humoral immunity is induced by intramuscular injection of plasmid DNA containing NP gene. DNA Cell Biol. 12, 771-776. doi: 10.1089/dna.1993.12.771

Zhang, Y., Yang, S., Zhao, X., Yang, Y., Li, B., Zhu, F., et al. (2014). Immune enhancement of Taishan Robinia pseudoacacia polysaccharide on recombinant Proteus mirabilis OmpA in chickens. Int. Immunopharmacol. 22, 236-241. doi: 10.1016/j.intimp.2014.06.036

Conflict of Interest Statement: The authors declare that the research was conducted in the absence of any commercial or financial relationships that could be construed as a potential conflict of interest.

Copyright (c) 2016 Zhu, Liu, Sun, Yu, Liu, Yang, Li, Wei and Zhu. This is an openaccess article distributed under the terms of the Creative Commons Attribution License (CC BY). The use, distribution or reproduction in other forums is permitted, provided the original author(s) or licensor are credited and that the original publication in this journal is cited, in accordance with accepted academic practice. No use, distribution or reproduction is permitted which does not comply with these terms. 